\title{
Food Security Status of Peri-Urban Modern Small Scale Irrigation Project Beneficiary Female Headed Households in Kobo Town, Ethiopia
}

\author{
Goitom Sisay Mengesha* \\ University College of Science, Department of Geography, Osmania University, Hyderabad, India \\ *Corresponding author: sisaygoitom@gmail.com
}

\begin{abstract}
This study has attempted to evaluate the household food security status of peri-urban modern small scale irrigation project beneficiaries. To attain this objective, a cross sectional survey method using structured questionnaire was employed on randomly selected 333 households. Household Dietary Diversity Score (HDDS), Food Consumption Score (FCS) and Per Capita Net Food Availability (NAF) were employed to evaluate the household food security status of the sample households. Furthermore, FGT family of indices were also computed. The HDDS result of this survey revealed that seven food groups were reported to be consumed with the mean HDDS value of 3.42, 3.84 and 3.21 for total samples, participants and non-participants respectively. The calculated FCS value for total samples, participants and non-participants was $42.74,44.89$ and 41.64 respectively. Furthermore, the computed NAF value revealed that of the total samples, 198 and 135 households were found to be food secure and food insecure respectively. This study illustrated household food insecurity, low dietary diversity and food consumption to be far more noticeable in non-participants than participants.
\end{abstract}

Keywords: food consumption score, food security/insecurity, female headed household, household dietary diversity, per capita food availability

Cite This Article: Goitom Sisay Mengesha, "Food Security Status of Peri-Urban Modern Small Scale Irrigation Project Beneficiary Female Headed Households in Kobo Town, Ethiopia." Journal of Food Security, vol. 5, no. 6 (2017): 259-272. doi: 10.12691/jfs-5-6-6.

\section{Introduction}

Food insecurity has been a problem of worry to humanity from the beginning of time. It becomes a prominent policy agenda as a result of recent food crises both at a regional and global level as well as renewed commitment from donor nations to address chronic hunger [1]. Since 1948 through the Universal Declaration of Human Rights, enhancing food security and reducing under nutrition have been promised [2].

The emergence of food security as a concept traced back to the 1974 United Nation Food and Agricultural Organization, World Food Conference in Rome at the time of global food crisis. This conference considered food availability as a central argument which stated "a secure, adequate and a suitable food supply for everyone”. Then, the 1996 World Food Summit and the United Nations Millennium Declarations (2000) targeted to halve the world's hungry people by 2015 [3].

Despite considerable efforts and some progress made, it seems that the goals are far from being achieved by many countries as chronic hunger in the world has increased rapidly [3,4,5]. According to [6], food security is generally about to deteriorate at the aggregate level as the share of population that is food insecure is projected to rise over $15 \%$ by 2025 . The poorest, landless and female headed households are the hardest hit [4]. Thus, problems related to increasing food availability, feeding the population, improving their nutritional status and reducing poverty levels continues to confront decision makers in many countries [5].

The latest report of [7] estimated that about 795 million people globally are believed to be undernourished; out of which the vast majority (780 million) lived in the developing world in the period 2014-16. The report revealed that Africa and Sub-Saharan Africa had 232.5 and 220 million undernourished people respectively in the specified time.

Despite the design and implementation of successive national food security strategies as well as considerable development potential, transitory food insecurity and poverty in Ethiopia are overwhelmingly perpetuated issues for several decades. Many households in Ethiopia are unable to buy or grow enough food to feed their families and need food aid as well as food imports each year for their survival $[8,9]$.

The history of famine in Ethiopia is thought to be as old as the history of man who ever lived in it perhaps 250 BC. However, available literature on recorded history of famine in Ethiopia refers to the $19^{\text {th }}$ and the $20^{\text {th }}$ centuries $[8,10]$. The country has faced some 44 severe famine catastrophes. Drought has been occurring in Ethiopia at a frequency of every 3 to 5 years which makes the country to be one the world's food aid dependent countries. Due to 
poor rain and effects of the El Niño, Ethiopia experienced its worst drought in 50 years where 9.7 million people were in need of emergency assistance in August 2016 [11]. Food insecurity exists when people lack secure access to sufficient amount of safe and nutritious food for normal growth and an active and healthy life [7].

Ethiopia is the least urbanized nation where its degree of urbanization in 2015 was $19.5 \%$ [12] and projected to reach $38 \%$ in 2050 [13]. On the other hand, the nation has the highest rate of urbanization; between the last two censuses (1994 and 2007), urban population has increased at an average annual growth rate of $4.9 \%$ [14]. Such increase in the size and proportion of the urban population has brought with it a new challenge of widespread and increasing urban poverty, a high unemployment rate, low governance capacities, weak infrastructure, poor municipal finance in cities and high demand for agricultural products [15].

As of the [16] report, 29.6\% of the Ethiopian population lives below the poverty line: of which $30.4 \%$ and $25.7 \%$ lives in rural areas and urban areas respectively. Poverty is a driving force for household food insecurity and food insecurity again, impoverishes a household. As a result, explanations about poverty and food insecurity are inseparable as they are among the undesirable livelihood outcome $[8,17]$. The problem of food insecurity which was hardship borne largely for the rural population is recently becoming a growing problem among the poor and the disadvantaged population in Ethiopian urban areas [18]. Official statistics have also revealed that recently urban poverty in Ethiopia has been growing at a rapid rate than rural poverty. For instance, between 1995/96-1999/00, urban poverty has increased by $11.1 \%$ while rural poverty has declined by $4.2 \%$ [19]. In response to soaring food prices as of 2007 and disrupted food supplies, many urban and peri-urban poor families have no alternative than to turn to urban and peri-urban irrigated agricultural activities for their livelihood and survival. Urban and peri-urban food production is in many cases a response of urban poor as a survival strategy [20,21]. Urban and peri-urban irrigated agriculture, mostly practiced by women and female headed households have the benefit of market proximity and freshness.

To meet the food demands of its rapidly growing population, it is expected that Ethiopia must double its cereal production by 2025. Irrigation as one integral part of water sector is a means by which agricultural production can be boosted to meet the growing food demand of the country [22]. As Ethiopia has a significant potential of irrigation both in terms of the available land and water resource, the government has prepared a water sector development program to be implemented between 2002 and 2016. The estimated total irrigable land of Ethiopia is 5.3 million hectares; of which potential irrigable area, only 4 to $5 \%$ (640,000 hectares) is under irrigation development [23]. In line with this, development and expansion of small-scale irrigation and rainwater harvesting strategies particularly in arid and semi-arid peri-urban and rural areas of the country become central to Ethiopia's policies and strategies [24]. Such schemes are intended to sustainably improve the food security and food self-sufficiency both at individual and national level through double cropping [25].

As the study area has been identified amongst the drought prone, moisture deficit and the people are food insecure, efforts have been made by KGVDP and Amhara Water Works Construction Enterprise office to expand the practice of modern small scale irrigation since 2003. As stated in [26] document, as of the commencement of the program, out of 17000 hectare of irrigable land, only 1794 hectares of land have been irrigated and benefiting 5744 households; of which 3844 (66.92\%) were male headed and the rest 1900 (33.08\%) were female headed. Measuring the effectiveness and efficiencies of Policies, programs and projects targeted towards improving food security is a major and challenging task for any institution and governments. Furthermore, due to the complex and multidimensional nature of food security looking for better measures of food security still remains a major challenge [5].

There is also no consensus as there are conflicting evidences from different projects and regions about the performance, sustainable and equitable role of small scale irrigation to household food security. Moreover, to the best of the writer's knowledge, in the study area no study has been conducted so far targeting female headed households. The purpose of this study was therefore to evaluate the household food security status of peri-urban modern small scale irrigation project beneficiary female headed households in Kobo town, Ethiopia.

\section{Material and Methods}

\subsection{Study Area Description}

This study was conducted in Kobo town and its surroundings. The town is the administrative centre of Raya Kobo Wereda (district) and Kobo town administration with five kebeles (the lowest administrative unit in Ethiopia). It is situated in the north-eastern tip of Amhara National Regional State, north Wollo administrative zone, Ethiopia [27].

The town lies on Addis Ababa-Mekelle national highway, about 570 kilometers north of Addis Ababa (the national capital) with a geographical coordinates between $11^{\circ} 54^{\prime} 04^{\prime \prime} \mathrm{N}$ and $12^{\circ} 20^{\prime} 56^{\prime \prime} \mathrm{N}$ latitude and between $39^{\circ} 25^{\prime} 56^{\prime \prime} \mathrm{E}$ and $39^{\circ} 49^{\prime} 04^{\prime \prime} \mathrm{E}$ longitude. The landscape of the Wereda is characterized by a broad fertile plain (65\%) whereas the rest $20,6,5$, and $4 \%$ are mountainous, rugged, gorges and swampy respectively. In the study Wereda altitude ranges from 1400-3100 meter above mean sea level where the average altitude is 1500 meter above mean sea level [27].

The study Wereda has an aggregate human population of 239, 504 of which 120, 383 (50.26\%) were men while the remaining 119,121 (49.74\%) were women. Out of the total population, 33,135 populations $(20.15 \%)$ are urban dwellers; of these urban dwellers male and female population constitutes 16311 (49\%) and 16824 (51\%) respectively. The study town had a population density of 119.7 persons per square kilometer with a total area of $2001.57 \mathrm{~km}^{2}$ [28]. 


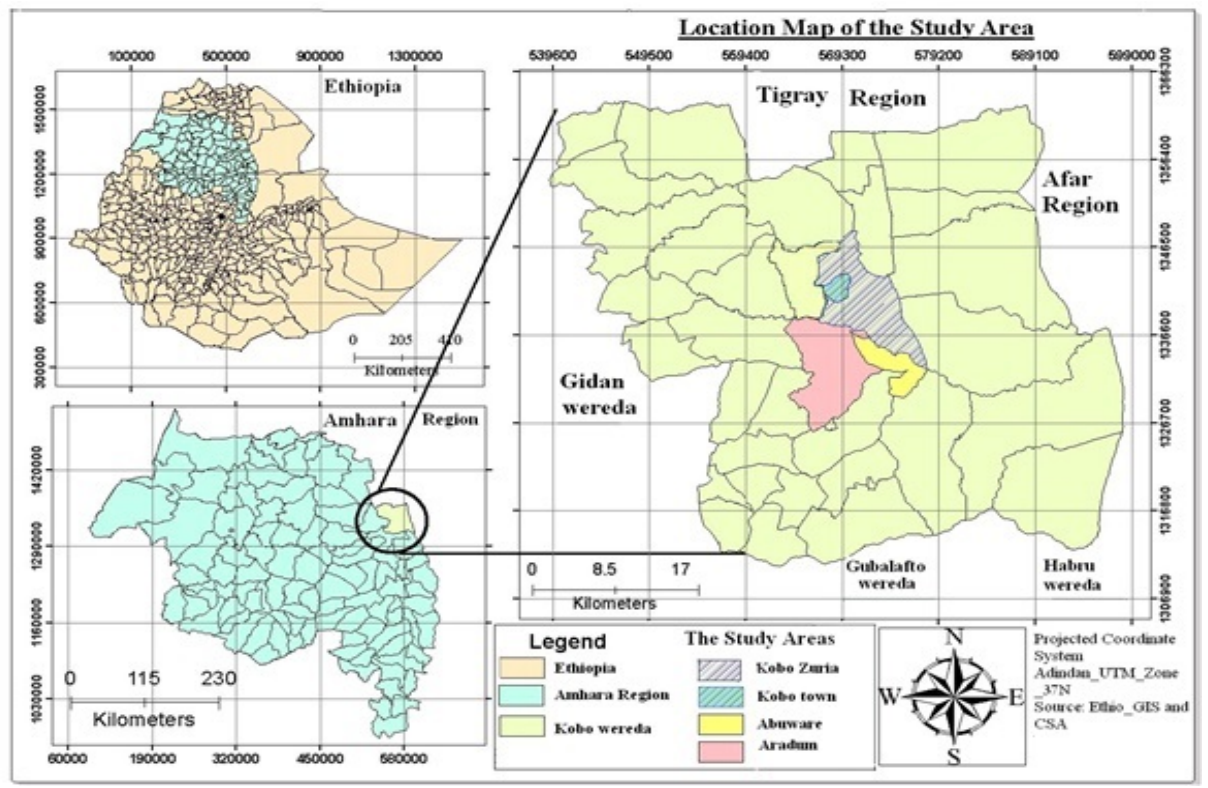

Figure 1. Location map of the study area

Agriculture practiced in the suburban areas of the study town serves as the main economic stay and means of livelihood to the majority of the town's people. It is characterized by traditional mixed farming as it includes both crop production and livestock rearing, dependent mainly on rainfall. The main crops produced through rainfall are cereals (Teff, sorghum and maize) and pulses (chick peas). Teff is a very fine, like cereal, scientifically known as Eragrostis tef. Furthermore, as of 2003, horticultural crops (onion, tomato, pepper) and fruits such as Mango and Avocado are being produced with the help of modern small scale irrigation [27].

The agro-climatic features of the district is characterized by three agro-ecological zones locally known as; "Dega" or Temperate (10.7\%), "Weyna Dega" or Sub-tropical (61.8\%) and "Kolla" or Tropical (27.5\%). It experiences low and erratic rainfall with a mean annual rainfall of 670 mm where maximum amount of rainfall happens during August. Rainfall distribution is bimodal where the main rain season occurs between July and September while the small rainy season is from January to April. The annual temperature ranges from the least $19^{\circ} \mathrm{C}$ to the highest $33^{\circ} \mathrm{C}$ where $23.1^{\circ} \mathrm{C}$ is a mean annual temperature [27].

\subsection{Research Design}

Research designs are the specific procedures involved in the research process; data collection, measurement, data analysis and report writing $[29,30]$. This study adopted the cross- sectional survey technique to collect primary data as a survey technique is popular and ideal mode of observation in the social sciences. On a cross-sectional survey design data are collected from samples at one specific point in time. According to [31], surveys are suitable for descriptive, explanatory or exploratory studies. Survey is especially ideal for studies that have individual people as units for analysis. As a result, survey is ideal for this study as it centred both the individual and the household as units of investigation and analysis. The head of the household served as the chief respondent to whom the study questionnaire was administered.
To evaluate the household food security status of female headed households, a combination of qualitative and quantitative data analysis techniques were used as it gives the chance to look the multiple dimensions of food security. The core argument for a mixed method design was that the combination of both forms of data provides a better understanding of a research problem than either quantitative or qualitative data by itself. Mixed method designs are procedures for collecting, analysing and mixing both quantitative and qualitative data in a single study or in a multiphase series of studies [30].

\subsubsection{Nature of Data and Method of Acquisition}

Both primary and secondary sources of data were used to address the research question. Primary data was collected from sample female household heads (both participants and non-participants) through structured questionnaires. This method was preferred among the other techniques because it could reach to the relatively large number of respondents. Most of the items of the structured questionnaires were close ended with some partially open ended items. As the respondents were female heads, collecting data about the food items served for the household members was easy as they are more responsible for the household food preparation. The data were collected through trained assistants and by the researcher after conducting the appropriate test on the constructed questionnaires. Moreover, Key informant interviews, Focus Group Discussion (FGD) and personal observation were also employed.

In-depth Key Informant Interviews were administered by the researcher himself with semi-structured open ended questionnaire to five female headed households and three officials from Kobo Girana Valley Development Programme on issues related to irrigation and household food security. Key informants provide detailed information on key issues that were not provided by other respondents.

Focus Group Discussions were held to gather in-depth information on the concepts, perceptions and ideas of a group pertaining to irrigation and Food security. Accordingly, by preparing checklists and triangulating issues, subsequent 
discussions were held by forming three groups (composed of a minimum of seven members) from the three study kebeles.

As indicated in [29], to diminish subjective bias, to relate the information obtained under mentioned methods to what is currently happening and as it relatively demands less of active cooperation on the part of the respondent, personal observation was also carried on irrigation sites and homes of respondents.

For reference purpose or to use as benchmarks against which the findings of a study can be tested, secondary data sources like books, articles and other unpublished reports related to the issue were also consulted.

\subsubsection{Sample Size and Sampling Techniques}

Multi-stage sampling procedure was employed to select sample households. Accordingly, in the first stage, the study town was selected purposively due to its familiarity to the researcher and extensive implementation of modern small scale irrigation projects. In the second stage, out of 41 modern small scale irrigation projects located in the study Wereda, 15 irrigation sites situated in the three kebeles namely Kobo Zuria, Aradum and Abuware were selected purposively; due to their accessibility, proximity to the study town and number of irrigation beneficiaries. These irrigation sites covered 946 hectares of land and are benefiting 2367 household heads of which 1619 (68.40\%) are male headed and 748 (31.60\%) are female headed households. In the second stage, to obtain representative samples, the sample size was determined through [32] online sample size determination software. The size was calculated using 95\% confidence level and 4\% margin of error (confidence interval). As a result, 333 female headed households (44.52\%) who are beneficiaries of peri-urban modern small scale irrigation; both participants (113) and non-participants (220) proportionate to their number were incorporated in this study through simple random sampling technique. The Water User Association members' registry was used as a sampling frame. On the other hand, purposive sampling technique was also used to identify Key Interview Informants and Focus Group Discussion members.

\subsubsection{Data Analysis}

To evaluate the household food security status of female headed households, a combination of qualitative and quantitative data analysis techniques were used as it gives the chance to look the multiple dimensions of food security. Descriptive and inferential statistics techniques such as arithmetic mean, percentage and Standard deviation were used to analyse the household food security situation of sample respondents. Bivariate analysis using cross tabulations were also done to identify the relationship between participation in irrigation and household food security status. Accordingly, chi-square and t-test were employed to test the statistical significance of dummy and mean value of continuous variables.

Literature on household food security distinguished two indicators of household food security; outcome and process indicators of food security. Outcome indicators are proxies for food consumption measures either directly as food expenditure and caloric consumption or indirectly through nutritional assessment (anthropometric indicators), subsistence potential ratio or storage estimates. Process indicators which reflect food supply and food access not only the food security situation but also the degree of vulnerability to food insecurity Maxwell and Frankenberger, 1992 in [33]. However, because of its multi-dimensional (Diet quality and quantity, psychological, social and cultural dimensions), broad and dynamic nature, identifying an appropriate indicator of food security remains a challenging task [34]. As a result, the search for better measures of food security that captures all aspects of food security still remains a major challenge [5]. Hence, many indicators of food security had been devised and employed by different organizations; according to [33] there are approximately 450 indicators and 200 definition of food security.

Despite the progresses made in devising appropriate measures, the popular indicators of food security still tend to provide information only on one of these dimensions at a time. Accordingly, use of more than one food security indicator is a recommended remedy as one indicator could not wholly explain food security $[1,35]$. Hence, to evaluate the household food security status of female headed peri-urban modern small scale irrigation project beneficiaries, Household Dietary Diversity Score (HDDS), Food Consumption Score (FCS) and per capita Net Food Availability (NAF) were employed as an outcome indicator. These measures are the product of food access, availability, stability and utilization dimensions of food security. Furthermore, compared to income based measures of household food security, consumption based food insecurity measure (HDD and FCS) were preferred for this study as they pretend to reflect household's ability to meet their basic needs, less vulnerable to measurement errors and its closeness to the utility that people effectively extract from income [36].

The survey was held at normal or usual days (not at special occasions) immediately prior to the harvest as it serves as a baseline for monitoring change due to an intervention. Food is relatively widely available immediately after the production season and starts to dwindle as the lean season approaches. Moreover, as eating outside the home is not a common practice in the study area, application of the questionnaire at the household level was preferred than at the individual level.

HDDS was employed for this study as it is a good indicator of food and nutrition security for various reasons. First, it correlates with measures of food consumption and are a good measure of household food access. Second, a varied diet is a worthy outcome in itself. Third, more diet variety is associated with a number of improved outcomes, child anthropometric status, improved haemoglobin concentration, reduced risk of mortality from cardiovascular disease and incidence of hypertension. Lastly, diet diversity scores can be collected through household surveys and can be used to examine Food and Nutrition Security at individual and intra-household levels but it cannot necessarily indicate the quantity of food consumed [2,37,38]. A study by [39] using data from Mali and [37] in their multi-country analysis of data from 10 countries assessed whether household dietary diversity could be used as indicator of household food security or not. Finally, they concluded that dietary diversity holds promise as a means of measuring food security. An empirical study in Ethiopia by [40] also verified that households with better dietary diversity were able to have 
better diet quantity. Moreover, dietary diversity is also recommended as an objective to be included in each country's food based dietary guidelines [41]. On the other hand, the major challenge of employing Dietary Diversity Score is absence of international consensus regarding the number of individual foods or food groups used to calculate the dietary diversity score and the threshold points of low, medium and good diversity scores which affect the comparability and generalizing of findings [4,42].

Dietary Diversity represents the number of different foods or food groups consumed by a household over a given reference period. It is measured by summing the number of foods or food groups consumed over a reference period. The reference period usually ranges from 1 to 3 days but 7 days is also often used and periods of up to 15 days have been reported [42]. For this study, following the recommendation of [43] and findings of [38], the recall period of 24 hours was chosen. It is less subject to recall error, less cumbersome for the respondent and also conforms to the recall time period used in many dietary diversity studies. It was also proved to be very consistent in the case of Ethiopia [38].

With regard to the choice between food items and food groups a study by [39] using data from Mali testify that food group diversity was a stronger predictor of dietary quality than the simple count of individual food. Accordingly, following the work of [39] and because of its simplicity, for this study I therefore preferred food groups instead of individual foods for the analysis of diet diversity. Furthermore, the selection of food groups was done based on the prior knowledge of common household dietary patterns and food systems among the study area as well as the guidelines of Food and Agriculture Organization of the United Nations [43]. Food group refers to a collection of food items that have similar caloric and nutrient content.

To estimate the HDDS, household heads were asked whether their family members had eaten the listed food groups or not within the last 24 hours prior to the survey. Thus, a consumption of each food groups was given the value of 1 if it was consumed by the household members and a value of 0 if not. As a result, seven major food groups namely (1) main staples, (2) pulses and legumes, (3) dairy products, (4) meat, (5) oils and fats, (6) vegetables and (7) fruits were reported to be consumed by the sample households in the reference period. Finally, the alternatives were summed and the value ranges from 0 to the maximum of 7 .

Following the thresholds of $[44,45,46,47]$, the cut-off points of seven or more food groups, four to six food groups and less than four food groups were employed to segment the calculated HDDS as high, medium and low dietary diversity scores respectively. Furthermore, the cut-off points of medium and high HDDS were used to designate nutritionally adequate dietary diversity while low HDDS was used to indicate nutritionally inadequate dietary diversity [43,46,47].

FCS is a composite score calculated based on dietary diversity, food frequency and relative nutritional importance of different food groups consumed by household members. Using standard seven day food frequency data, FCS was calculated first by grouping all the food items into specific food groups (Main staples, pulses, vegetables, fruits, meats and fish, milk, sugar and honey, oil and fats with a weight of 2,3,1,1,4,4,0.5 and 0.5 respectively), second sum all the consumption frequencies of food items of the same group and recode the value of each group above 7 as 7 , thirdly multiply the value obtained for each food group by its weight that is based on its nutrient content to create new weighted food group scores and at last we sum the created new weighted food group scores. Finally, employing the standard and calibrated FCS thresholds, sample households were categorized in to three groups; poor, borderline and acceptable food consumption with a value of $0-28,28.5-42$, and $>42$ respectively [48]. These threshold points were employed by [14] in the household food security study of Ethiopian urban areas. Moreover, this method was also proved to be applicable in Ethiopian food security studies [38,49].

$$
\begin{aligned}
\text { FCS }= & A_{\text {staple }} X_{\text {staple }}+A_{\text {pulse }} X_{\text {pulse }}+A_{\text {veg }} X_{\text {veg }}+ \\
& A_{\text {fruit }} X_{\text {fruit }}+A_{\text {animal }} X_{\text {animal }}+A_{\text {sugar }} X_{\text {sugar }}+ \\
& A_{\text {dairy }} X_{\text {dairy }}+A_{\text {oil }} X_{\text {oil }}
\end{aligned}
$$

Where: FCS=is Food Consumption Score

$\mathrm{X}_{\mathrm{i}}=$ is Frequencies of food consumption = number of days for which each food group was consumed during the past 7 days

$\mathrm{A}_{\mathrm{i}}=$ is weight of each food group

The Net Available Food (NAF) for the sample households was computed using a modified form of a simple equation known as Household Food Balance Model adopted from FAO's Regional Food Balance Model by Degefa in 1996 [3]. The choice of Household Food Balance Model for this survey was inspired by the scientific work of many studies such as [3,10,50,51]. Employing this model they also estimated 5\% and 10\% of the total produces for seed reserves and post-harvest losses respectively. In developing countries post-harvest loss is a major constraint in achieving food security and it occurs in the levels of pre-processing, storage, packaging and marketing [5].

Data used for the computation of NAF for this study was generated from the field survey embarked on to assess the period from October 2015 to September 2016. Household Food Balance Model is specified as;

$$
\begin{aligned}
\mathrm{NGA}= & (\mathrm{GP}+\mathrm{GB}+\mathrm{FA}+\mathrm{GB}+\mathrm{GG}) \\
& -(\mathrm{HL}+\mathrm{GU}+\mathrm{GS}+\mathrm{GV})
\end{aligned}
$$

Where, NGA= Net grain available/year/household $\mathrm{GP}=$ Total grain produced/year/household $\mathrm{GB}=$ Total grain bought from market/year/household

FA= Quantity of food aid obtained/year/household

$\mathrm{GB}=$ Total grain borrowed /year/household

$\mathrm{GG}=$ Total grain obtained through gift or remittance/year/household

$\mathrm{HL}=$ Post harvest losses/year (10\%)

GU=Quantity of grain reserved for seed/year/household (5\%)

GS=Amount of grain sold/year/household

$\mathrm{GV}=\mathrm{Grain}$ given to others within a year

Following the empirical works of [51] and [52], the computed NAF was therefore compared against 2.25 quintals of food grain (225 kg) per Adult Equivalent per year, which is roughly cereal equivalent of the 
recommended national average daily caloric requirement for a moderately active adult (2100 kcal/person/day set by WHO, FAO and Ethiopian Government). Finally, the difference between net food grains available and food grains demanded by a household was used to determine the food security status of the sample household. Thus, households whose available average net annual per capita food grain greater than or equal to 2.25 quintals of food grain were regarded as food secure, whereas households whose net available per capita food grain had fallen below the threshold were labelled as food insecure. For this purpose, the family size of each household was converted into Adult Equivalent family size which considers age and sex of each family member of the household. Furthermore, the procedure of [53] was also employed to compute the incidence, depth and severity of household food insecurity. The Foster-Greer-Thorbecke (FGT) measure is given as:

$$
P_{\alpha}=\frac{1}{N} \sum_{i=1}^{q}\left(\frac{Z-Y_{i}}{Z}\right)^{\alpha}
$$

Where: $\mathrm{N}=$ Total number of sample households under the study.

$\mathrm{Y}_{\mathrm{i}}=$ is the measure of per adult equivalent annual net food grain available to the $i^{\text {th }}$ household

$\mathrm{Z}$ = represents the cut-off point between food secure and food insecure households (2.25 quintals of food grain per annum per adult)

$\mathrm{q}=$ is the number of food insecure households and

$\alpha=$ is the weight attached to the severity of food insecurity

In FGT index, $\mathrm{Y}_{\mathrm{i}} \geq \mathrm{Z}$ mean the specified household is food secure.

Following [33], using FGT family of indices, the head count ratio, food insecurity gap and squared food insecurity gap were computed to have in-depth insight among sample food insecure households.

Head count ratio estimates the percentage of sample households whose available annual per capita food grain is falling below the minimal requirement (2.25 quintals of food grain per adult per annum). Giving no weight to the severity of food insecurity is equivalent to assuming that $\alpha$ $=0$, becomes the ratio between number of food insecure households with the total sample household size. Accordingly, the formula collapses to $P(0)=\frac{q}{N}$.

Giving equal weight to the severity of food insecurity among all food insecure households is equivalent to assuming that $\alpha=1$. Summing the numerator gives the food insecurity gap. The food insecurity gap index measures the mean depth of food insecurity among the food insecure female headed households. It is the mean proportion by which the food security status of the food insecure households falls below the minimum level of food grain requirement. It is mathematically expressed as:

$$
\text { Food Insecurity Gap Index }\left(P_{1}\right)=\frac{1}{N} \sum_{i=1}^{q}\left(\frac{Z-Y_{i}}{Z}\right)
$$

The food severity index (or squared insecurity gap) characterizes the amount of resources that will be required to bring all the food insecure households to the subsistence level. In other words, it will provide the possibility to estimate the required resources to eradicate household food insecurity through proper targeting. Giving more weight to the household food security severity among the most food insecure households is equivalent to assuming that $\alpha>1$. Accordingly, setting FGT $(\alpha=2)$, squared insecurity gap is mathematically written as:

$$
\text { Food Severity Index }\left(P_{2}\right)=\frac{1}{N} \sum_{i=1}^{q}\left(\frac{Z-Y_{i}}{Z}\right)^{2}
$$

Finally, to evaluate the relationship between Household Dietary Diversity Score, Food Consumption Score, and Net Available Food, Pearson Correlation Coefficient was employed.

Qualitative data mainly opinions and perceptions obtained from open ended questionnaires, Key Informant Interviews, Focus Group Discussions and personal observations were also analyzed qualitatively by using common expressions and similar opinions.

Microsoft Excel and SPSS version 23 software was used to organize and analyze the collected primary data.

\section{Hypothesis}

It is hypothesised that other variables being constant, participant households will have better Household Dietary Diversity Score, Food Consumption Score and Per Capita Net Food Available than non-participant households.

\section{Results and Discussion}

The concept of food security is understood and used differently depending on the context, time frame and geographical region in question [5]. The term originated in 1974 when the World Food Conference first gave an official definition of food security as "availability at all times of adequate world food supplies of basic foodstuffs to sustain a steady expansion of food consumption and to offset fluctuations in production and prices" ([54], pp. 27). This definition focused exclusively on the 'availability' aspect of food security. This definition was a reflection of the problems caused by the worldwide food crisis in the 1970s. In 1983, FAO extended this concept to embrace food access by vulnerable people, implying that the demand side of food security is at least as important as its supply side. This version suggests that food security should "ensure that all people at all times have both physical and economic access to the basic food that they need" ([54], pp. 27). In 1986, the World Bank report on "Poverty and Hunger", further explained the concept of food security. As of this report, food security is defined as "access of all people at all times to enough food for an active, healthy life" ([54], pp. 27). This concept also embraces malnutrition, poverty and food safety issues.

The most widely accepted definition of food security, generated in 1996 at the World Food Summit emphasized the multidimensionality of food security. As of this Summit "food security, at the individual, household, national, regional and global levels is achieved when all 
people, at all times, have physical and economic access to sufficient, safe and nutritious food to meet their dietary needs and food preferences for an active and healthy life”. Furthermore, this definition of food security has four dimensions; availability, access, utilization and stability. On the other hand, "food insecurity exists when people do not have adequate physical, social and economic access to food as defined above” ([54], pp. 28).

Food availability reflects the availability of sufficient quantities of food of appropriate quality, either by domestic production or food imports. It is a measure of the amount of food that is and will be physically available in a population during a certain period of time. Food availability corresponds to, not just physical but also energy supplies of food, implying a strong connection with diets [2,55]. Diet quantity available to a household can be measured by daily food energy consumption per capita or per adult equivalent, and percentage of households or people that are food energy-deficient. The second diet quantity indicator is the percentage of households in a population group that do not consume sufficient dietary energy. If the estimated total energy in the food that the household acquires daily is lower than the sum of its members' daily requirements, the household is classified as food energy-deficient or food insecure and vice versa.

Food access captures whether people have enough resources to acquire nutritious food for a healthy diet. It covers both economic access to food at the household level and physical access to food in the market, and is measured in terms of income and food prices for the former, and infrastructure to market outlet for the latter. Consequently, poverty rates and purchasing power parity indices are strongly linked to food access [55]. A household's ability to spend on food is a good indicator of food access at the household level. Household food access is measured through food or nutrient intake at the household level reported in adult equivalent [5].

Food utilization which emphases on assuring the biological utilization of food has two elements; one is based on indicators representing under nutrition for children under the age of five, while the other reflects food quality and hygiene conditions. Therefore, utilization of food can be reached through adequate diet, clean water, sanitation and health care all of which are necessary for nutritional well-being [55]. This dimension of food security gives due attention for non-food inputs in food security. The consumption of foods both in quantity and quality that is sufficient to meet energy and nutrient requirements is a basic measure of food utilization. According to Frankenberger et al. (1997, pp.1) in [2] " $a$ person is considered nutrition secure when she/he has a nutritionally adequate diet and the food consumed is biologically utilized such that adequate performance is maintained in growth, resisting or recovering from disease, pregnancy, lactation and physical work”. Data on nutrient requirements and recommended intakes are vital to estimate food utilization. Food intake comprises Protein and other nutrients, but energy intake is one of the main parameters and is extremely important in improving food utilization. The National Academy of Sciences (1995) has arrived at a figure of $2100 \mathrm{kcal}$ per day for use in food emergency situations, which is based on an assumption of light activity [5].
Stability of food supplies captures the ability of people to access adequate food at all times. Hence, it refers to both the availability and access dimensions of food security [55].

Measuring food security at the national, regional, community, household and individual level is vital for the development of appropriate policy and program options [5]. In this study, the focus was on household (a unit of people living together and headed by a household head) food security as it is a basic social unit in a society. At the household level, a household is labelled as food secure when it has access to the food needed for a healthy life for all of its members (adequate with regard to quality, quantity and safety as well as culturally acceptable) and when it is not at unwarranted risk of losing such access (UN ACC/SCN, 1991) in [56].

For this study household food security implied whether the household can produce sufficient food from their own production or purchase food grains of the right quality and quantity in the local market which clearly implies availability of enough food and the capacity of the household to acquire it respectfully. Therefore, the survey result of Household Diet Diversity Score, Food Consumption Score as well as the Net Available Food Grain values of the sample households are presented below.

\subsection{Households Diet Diversity Score (HDDS)}

The higher the Diet Diversity Score, the more food groups were consumed, the more varied the diet and therefore, the higher the nutritional quality of the diet. For this study the researcher simply generated HDDS by summing up all the food groups reported to be consumed by the sample household members within 24 hours prior to the survey.

The effect of commercialization on food consumption and nutrition is a complex and controversial subject; opponents of commercialization insist that if the resources that are used to produce agricultural export crops were used instead to produce food for the local economy, undernourishment can be minimized. On the other hand, advocates argue that exploiting of comparative advantage; commercialization could raise farm incomes and improve nutrition [5]. The empirical study of [40], found that households with irrigation water access were encouraged to produce cash crops more commanded in the market and the risk in the marketing of these crops was ultimately damaging their nutritional position. Irrigator households allocate relatively more land to more risky perishable cash crops and less land to produce staples (food crops).

Depicted in Table 1, the survey result of this study revealed that, seven food groups were reported to be consumed with the minimum, maximum, mean and standard deviation value of 3, 6, 3.42 and 0.71 HDDS respectively. Moreover, the mean HDDS for participant and non-participant households was computed to be 3.84 and 3.21 respectively. Comparing irrigation participants from non-participants in terms of mean HDDS, the independent sample test was associated with a statistically significant effect $t(134.759)=6.738, \mathrm{p}<0.01$ at $99 \%$ level of significance. This significant value of the t-test states the existence of HDDS discrepancy between sample participant and non-participant households. Hence, it can 
be inferred that compared with non-participants, participant households who cultivate their irrigable land enjoy relatively a diversified diet. On the other hand, non-participant households who share crop out their farm land and forced to lose half of their farm produces with limited decision power on preference and quality of crops to be produced, were exposed for low dietary diversity.

Table 1. Household Dietary Diversity Score of the sample households

\begin{tabular}{|c|c|c|c|}
\hline Households & Household Diet Dive & Score & $\mathrm{t}$-value \\
\hline \multirow{4}{*}{ Total } & Minimum & 3.00 & \multirow{12}{*}{$6.738 * * *$} \\
\hline & Maximum & 6.00 & \\
\hline & Mean & 3.42 & \\
\hline & Standard deviation & 0.71 & \\
\hline \multirow{4}{*}{ Participants } & Minimum & 3.00 & \\
\hline & Maximum & 6.00 & \\
\hline & Mean & 3.84 & \\
\hline & Standard deviation & 0.95 & \\
\hline \multirow{4}{*}{ Non-participants } & Minimum & 3.00 & \\
\hline & Maximum & 5.00 & \\
\hline & Mean & 3.21 & \\
\hline & Standard deviation & 0.42 & \\
\hline
\end{tabular}

*** refers significant at 0.01 level

Source: computed from field survey, 2016

Besides to calculating the mean HDDS, an attempt has also been made to indicate which food groups were reported to be predominantly consumed by the sample households. Accordingly, as shown in Table 2 all the sample households reported to consume cereals and edible oils used for cooking during in the last 24 hours preceding the survey. The second most common food group contributed to the daily meals was pulses and legumes (86.5\%), followed by rarely consumed but rich in micronutrients vegetables (18.0\%), dairy products (15.9\%), animal protein (13.2\%) and fruits (8.7\%). Thus, cereals, oils as well as pulses and legumes were the dominant food groups reported to be consumed within the 24 hours recall period prior to the survey. In line with this study, the survey of [57] report reveals that, three food categories (cereals, edible oil and fat, and legumes) dominate the Ethiopian meal. Furthermore, a study by [44], revealed that a cereal flour made baked bread was eaten wrapping a sauce from a pulse crop or a vegetable crop or meat alone or less frequently mix of two or more of these. A mix of two or more of these was a common consumption habit in Ethiopia.

Table 2. Food Groups reported to be consumed by sample households in 24 hours recall period

\begin{tabular}{c|c|c|c|c|c|c}
\hline \multirow{2}{*}{ Food groups } & \multicolumn{2}{|c|}{ Total } & \multicolumn{2}{c|}{ Participants } & \multicolumn{2}{c}{ Non-participants } \\
\cline { 2 - 7 } & Yes & No & Yes & No & Yes & No \\
\hline Main Staples & 333 & 0 & 113 & 0 & 220 & 0 \\
\hline $\begin{array}{c}\text { Pulses and } \\
\text { legumes }\end{array}$ & 288 & 45 & 82 & 31 & 206 & 14 \\
\hline Dairy products & 53 & 280 & 39 & 74 & 14 & 206 \\
\hline Animal protein & 44 & 289 & 30 & 83 & 14 & 206 \\
\hline Oils & 333 & 0 & 113 & 0 & 220 & 0 \\
\hline Vegetables & 60 & 273 & 37 & 76 & 23 & 197 \\
\hline Fruits & 29 & 304 & 20 & 93 & 9 & 211 \\
\hline
\end{tabular}

Source: Computed from field survey, 2016
Lack of Dietary Diversity is a severe problem in developing world where diets are predominantly starchy staples (cereals high in carbohydrates, but low in nutrients and vitamins) with little or no animal products and vegetables [4,5]. Nationally, 58 and $30 \%$ of the Ethiopian households' consume four or fewer and three or fewer out of seven food groups respectively [58].

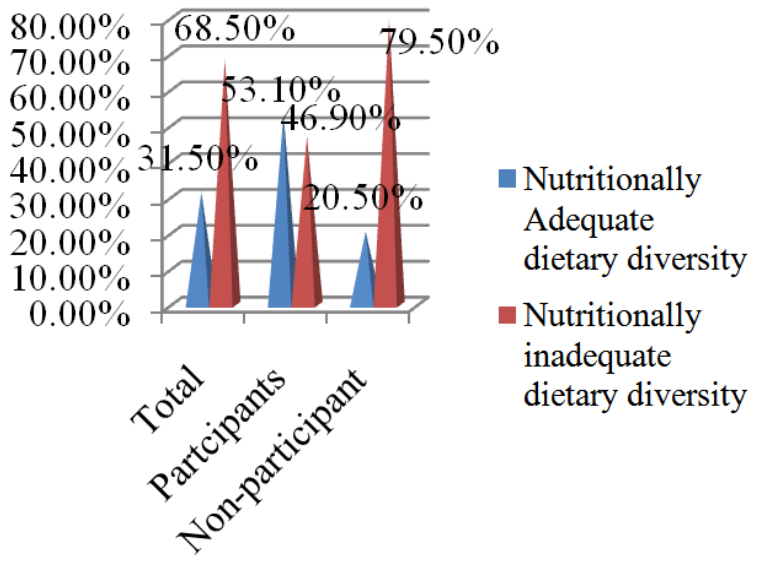

Figure 2. Sample Households' Household Dietary Diversity status (Source: Computed from field survey, 2016)

Setting the HDDS of seven or more food groups, four to six food groups and less or equal to three food groups as threshold points of high, medium and low HDDS respectively, as presented in Figure 2, 68.5\% of the sample households had low HDDS (nutritionally inadequate dietary diversity). The remaining, $31.5 \%$ of the sample households had medium HDDS (nutritionally adequate dietary diversity). Furthermore, 46.9 and $53.1 \%$ of participant households as well as 79.5 and $20.5 \%$ of non-participant households had low and medium measure of HDDS respectively.

As per the Focus Group Discussants', Key Informant Interview participants' opinion and personal observations, the problem of low HDDS of the sample households was related with lack of knowledge and awareness about nutrition, cultural preferences, participation in irrigation which resulted for the practice of mono-cash cropping (mainly onion), household's dependence on crop production as a means of employment, food and cash income, and the prevalence of severe drought in the survey year due to inadequate rain and effects of the El Niño. According to the officials of KGVDP, during in the last consecutive production years the production of onion and tomato in the study area contributed for more than 90 and $8 \%$ of the irrigated land respectively. In line with this, [59] also found that $89 \%$ of the sample farmers in Northern Ethiopia produce onion employing deep well irrigation.

The finding of this study exposed the need for tremendous effort for creating awareness among the nutritionally inadequate sample households about the need to diversify their food baskets to ensure balanced diets so as to improve their nutritional status.

\subsection{Food Consumption Score (FCS)}

The problem of food insecurity (Nutritional insecurity) may occur under adequate availability and accessibility 
due to problems related to consumption [10]. Hence, food consumption patterns are vital indicators of the food security status of households; households who often consume a wide variety of food items or food groups are more food secure than households who infinitely consume very alike food stuff [49]. To estimate food consumption pattern of female headed households, FCS was calculated at the household level over the period of a week preceding the survey. The score shows dietary diversity, food frequency and relative nutritional importance of different food groups consumed by household members. The calculated household FCS of this study displayed in Table 3 stated that the minimum, maximum and mean household FCS for the sample households was 37.5, 54.0 and 42.74 respectively. Moreover, the calculated mean household FCS also showed variation among participant (44.89) and non-participant households (41.64). The independent sample test was associated with a statistically significant effect $t(124.024)=7.438, \mathrm{p}<0.01$ at $1 \%$ probability level. This significant value of the t-test assured the existence of noticeable household FCS variation between participant and non-participant households. Therefore, based on the survey result, it can be said that compared with non-participants, participant households enjoy better FCS.

Table 3. Food groups reported to be consumed by sample households in a week period

\begin{tabular}{c|c|c|c|c|c|c}
\hline \multirow{2}{*}{ Food groups } & \multicolumn{2}{|c}{ Number of days a given food group was consumed by: } \\
\cline { 2 - 7 } & \multicolumn{2}{|c|}{ Total } & \multicolumn{2}{c}{ Participants } & \multicolumn{2}{c}{$\begin{array}{c}\text { Non- } \\
\text { participants }\end{array}$} \\
\cline { 2 - 7 } & Mean & SD & Mean & SD & Mean & SD \\
\hline Main Staples & 7.00 & 0.00 & 7.00 & 0.00 & 7.00 & 0.00 \\
\hline Vegetable & 0.52 & 0.69 & 0.84 & 0.90 & 0.35 & 0.48 \\
\hline Fruits & 0.16 & 0.46 & 0.34 & 0.68 & 0.07 & 0.25 \\
\hline $\begin{array}{c}\text { Animal } \\
\text { protein }\end{array}$ & 0.14 & 0.35 & 0.27 & 0.44 & 0.07 & 0.26 \\
\hline $\begin{array}{c}\text { Dairy } \\
\text { products }\end{array}$ & 0.23 & 0.58 & 0.58 & 0.84 & 0.05 & 0.22 \\
\hline Oils & 7.00 & 0.00 & 7.00 & 0.00 & 7.00 & 0.00 \\
\hline Sugar & 5.06 & 1.27 & 5.39 & 1.33 & 4.89 & 1.20 \\
\hline $\begin{array}{c}\text { Pulses and } \\
\text { legumes }\end{array}$ & 6.86 & 0.35 & 6.72 & 0.45 & 6.93 & 0.26 \\
\hline FCS & 42.74 & 3.26 & 44.89 & 4.52 & 41.64 & 1.45 \\
\hline t-value & & & $7.438 * * *$ & & \\
\hline
\end{tabular}

*** refers significant at 0.01 level, SD-Standard Deviation

Source: Computed from field survey, 2016

All the sample households reported regular consumption of main staples, edible oils, as well as pulses and legumes almost on a daily basis over the period of a week prior to the survey. Sugar with low nutrient value was also reported to be frequently consumed, on an average of 5.06 days a week. Vegetables (0.52 days per a week), dairy products ( 0.23 days per a week), fruits ( 0.16 days per a week) and animal proteins ( 0.14 days per a week) were the least frequently consumed food groups. Therefore, the survey result of this study clearly demonstrated the existence of inadequate diet for a healthy active life as animal proteins, fruits, dairy products and vegetables with moderate and high nutrient value were reported to be consumed least frequently over a period of a week prior to the survey. Consistent with this survey finding, the national Food Consumption Score survey of [57] also revealed that cereals (rice, sorghum, barley and wheat), edible oil and fats, and legumes characterize the Ethiopian meal in the last seven days prior the survey.

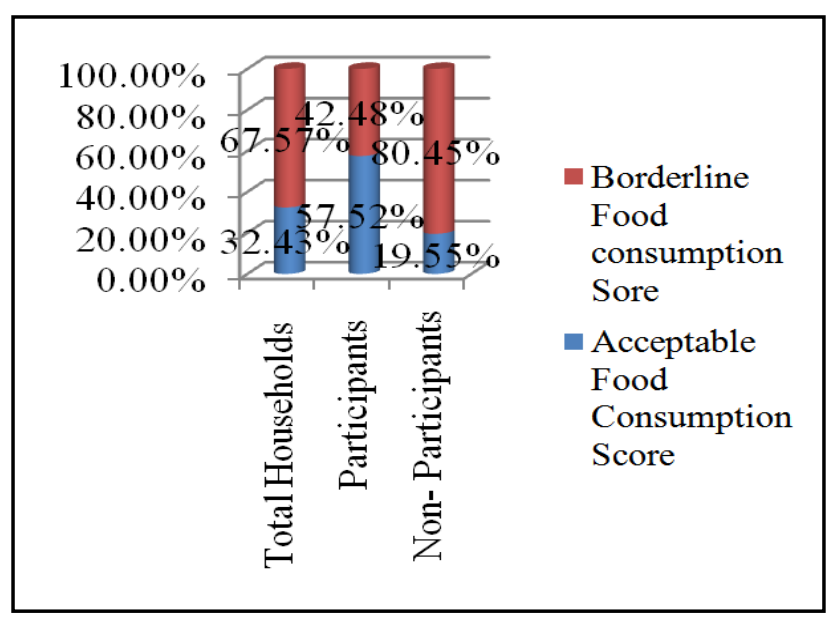

Figure 3. Percentage distributions of sample households based on FCS thresholds (Source: Computed from field survey, 2016)

Employing the standard and calibrated thresholds of [14] FCS, Figure 3 vividly revelled that a majority, 225 $(67.57 \%)$ of the sample households were found to be in the borderline food consumption group, while the remaining 108 (32.43\%) were clustered under the acceptable food consumption category. Moreover, 57.52 and 19.55\% of participant and non-participant households respectively fall under the acceptable FCS category, while 42.48 and $80.45 \%$ of the sample participants and non-participants respectively were grouped under the border line FCS.

The computed Household Dietary Diversity and household Food Consumption Scores of this survey are snapshots of the economic ability of a household to access a variety of foods during the time of data collection and cannot represent households' annual food consumption pattern. Accordingly, it also appears important to estimate the average annual per capita net food availability of the sample households.

\subsection{Net Available Food (NAF)}

Major dependence on rain-fed agriculture makes food security in Ethiopia to be highly sensitive to climate risks. For instance, the 2015/16 severe drought had an adverse effect on food availability and consequently on food security in the country in general and the study area in particular. This worst drought resulted in the minimal crop harvest, massive livestock death, very low livestock production, staple food price soaring and limited food availability.

Household Food Balance Model (HFBM) was employed to estimate the annual NAF of sample households. The model considered food grain available from households' own production, purchased and gifted grains on one hand and grain sold, post-harvest loss and seed reserve (for participant households only) on the other hand. To this end, NAF was employed as an indicator of food availability and household food security situation of the sample households.

The estimated annual NAF value for each respondent household was therefore compared against $225 \mathrm{~kg}$ of food grain, which is approximately cereal equivalent of the 
recommended average daily kilocalorie of 2100 for a healthy adult person. The variation between the available grain and the recommended grain was used to determine the household food security status of sample households. Thus, households whose annual NAF per capita food grain was greater than the recommended demand were regarded as food secure households, while those experiencing a food grain deficit were labelled as food insecure households.

To determine household level grain equivalent requirement, the average household size in Adult Equivalent was multiplied by the minimum acceptable weighted average food requirement of 2.25 quintals $(225 \mathrm{~kg}$ ) of food grain per adult person per year. The sample households' average household size measured in Adult Equivalent was 2.28. Hence, the total annual minimum food requirement for a sample household was estimated at 5.13 quintals $(513 \mathrm{~kg}$ of food grain equivalent). On the other hand, the survey result revealed that the total annual NAF grain for the sample total 760.09 Adult Equivalent household members from all sources for the surveyed year was 1769.47 quintals. This grand volume gave the average annual per capita NAF food grain volume of 2.52 quintals (5.75 quintals per household) which in turn was a bit greater than the minimum annual food grain requirement. Having this computed crude mean annual per capita NAF grain volume; it can then be inferred that all the sample households could be regarded as food secure given the fact that the annual average available per capita food grain volume was greater than the recommended food grain volume. Furthermore, the computed average annual Adult Equivalent per capita NAF grain volume for participant and non-participant households illustrated in Table 4 was 2.6484 and 2.4556 quintals respectively. Considering this estimated annual NAF grain volume, it can be understood that participant and non-participant households had variation in average annual Adult Equivalent per capita NAF grain amount. The independent sample test was associated with a statistically significant effect $t$ (331) $=2.265, \mathrm{p}<0.05$ at $5 \%$ probability level. This significant test value assured that there was relatively a significant mean annual Adult Equivalent per capita NAF grain volume difference between sample participant and nonparticipant households. Therefore, based on the t-test result, it is possible to infer that compared with non-participants, participant households enjoy a relatively better NAF grain quantity for the survey year.

Table 4. Descriptive statistics summary of per capita annual NAF food grain

\begin{tabular}{c|c|c|c}
\hline \multirow{2}{*}{ Households } & \multicolumn{2}{|c|}{ NAF/ADE/year (Quintals) } & \multirow{2}{*}{ t-value } \\
\cline { 2 - 3 } & Mean & SD & \\
\hline Total & 2.5210 & 0.74016 & \multirow{2}{*}{$2.265^{* *}$} \\
\hline Participants & 2.6484 & 0.84145 & \\
\hline Non-Participants & 2.4556 & 0.67508 & \\
\hline
\end{tabular}

** refers significant at 0.05 level, SD-Standard Deviation

Source: Computed from field survey, 2016.

According to the [60] study, in times of good weather, $75-80 \%$ of the annual agricultural produce in Ethiopia is estimated to be consumed at the household level. The survey result of the Household Food Balance model publicized in Table 5 also revealed that out of the total annual NAF grain volume, 73.31, 26.65 and $0.04 \%$ was generated from the respondents' own production, through purchase and obtained as a gift respectively. This in turn clearly designated that households' own production was the most important dietary source of energy and food availability in the survey period. In subsistence economies, household food security was largely linked to availability of food from household's own production than consumption of market purchased food. Thus, it can be said that during in the survey year sample households had subsistence economies.

Table 5. Sample households' total annual food available from all food sources

\begin{tabular}{l|c|c|c}
\hline Food grain & Total & Participants & Non-participants \\
\hline Own production & 2086.5 & 1266 & 820.5 \\
\hline Grain purchased & 758.45 & 321.7 & 436.75 \\
\hline Obtained as a gift & 1 & 0 & 1 \\
\hline Grand total & 2845.95 & 1587.7 & 1258.25 \\
\hline Grain sold & 712.5 & 555.5 & 157 \\
\hline Reserved for seed & 79.385 & 79.39 & 0 \\
\hline Post-harvest losses & 284.595 & 158.77 & 125.83 \\
\hline Total deduced & 1076.48 & 793.66 & 282.83 \\
\hline NAF & 1769.47 & 794.05 & 975.43 \\
\hline
\end{tabular}

Source: Computed from field survey, 2016

Employing the Adult Equivalent annual per capita threshold of $225 \mathrm{~kg}$ of food grain volume, as depicted in Table 6 out of the sample households, 198 households (59.46\%) with an average annual per capita Adult Equivalent NAF grain volume of 2.98 quintals were found to be food secure and the remaining 135 households (40.54\%) were food insecure with a mean annual per capita Adult Equivalent NAF grain volume of 1.85 quintals. The annual NAF survey result also portrayed the existence of household food security status disparity between participant and non-participant households. Where $65.49 \%$ of participants with an average annual per capita Adult Equivalent NAF grain volume of 3.01 quintals and $56.36 \%$ of non-participant households with a mean annual per capita Adult Equivalent NAF grain volume of 2.95 quintals were found to be food secure. Thus, as per the annual threshold of $225 \mathrm{~kg}$ of food grain, it can be inferred that participant households were more food secure than non-participants. However, the Chisquare test statistical association result showed no significant differences between participant and nonparticipant households in their food security status at all probability levels.

Table 6. Food Security Status of Sample households as per NAF/ADE/year

\begin{tabular}{|c|c|c|c|c|}
\hline \multirow{2}{*}{\multicolumn{2}{|c|}{ Households }} & \multicolumn{2}{|c|}{$\begin{array}{c}\text { NAF/ADE/year } \\
\text { (Quintals) }\end{array}$} & \multirow{2}{*}{$\begin{array}{c}\text { Chi- } \\
\text { square } \\
\text { value }\end{array}$} \\
\hline & & Mean & Std. Dev & \\
\hline \multirow{3}{*}{ Food Secure } & Total & 2.98 & 0.63 & \multirow{6}{*}{2.578} \\
\hline & Participants & 3.01 & 0.83 & \\
\hline & Non-participants & 2.95 & 0.47 & \\
\hline \multirow{3}{*}{$\begin{array}{c}\text { Food } \\
\text { insecure }\end{array}$} & Total & 1.85 & 0.16 & \\
\hline & Participants & 1.96 & 0.12 & \\
\hline & Non-participants & 1.81 & 0.16 & \\
\hline
\end{tabular}

Source: Computed from field survey, 2016 
Following the procedures of FGT family of indices explained in the methodology, head count index, food insecurity gap as well as severity of household food insecurity was computed. Moreover, as there was a mean annual per capita Adult Equivalent NAF grain quantity variation between sample food insecure participant and non-participant households, separate value of FGT family of indices were also calculated. Consequently, the survey result revealed that the estimated head count ratio or prevalence of food insecurity for the total food insecure sample households was 0.4054 ; of which 0.3451 and 0.4364 was for the food insecure participant and nonparticipant households respectively. This implies that 40.54, 34.51 and $43.64 \%$ of the sample households, participant and non-participant households respectively were not able to meet the stipulated minimum requirement. Hence, it can be deduced that the prevalence of food insecurity problem was fairly higher for non-participant households than participants. However, the Chi-square test statistical association result showed no significant differences between participant and non-participant households in their food security status at all probability levels.

\subsection{Extent of Household Food Insecurity}

To have an in-depth insight on how these food insecure sample households were far below the recommended food grain volume; household food insecurity gap was also computed. The rationale behind the calculation of food insecurity gap was to estimate the resources required to alleviate the problem of household food insecurity through proper targeting. Generally, as the food insecurity gap value gets larger, more resources are needed to lift them out of the food insecurity situation. Publicized in Table 7, the calculated food insecurity gap value for the total food insecure sample households, food insecure participant and non-participant households was found to be 0.0727 , 0.0153 and 0.0561 respectively. These estimated values further indicate that the problem of household food insecurity was not as such severe as the value tends towards zero; the degree of household food insecurity diminishes and requires less resource to lift the sample food insecure households out of food insecurity trap. Accordingly, if the Wereda officials mobilize and distribute resources that can meet and sustain 7.27, 1.53 and $5.61 \%$ of the food grain amount requirement of the sample total food insecure households, food insecure participant and non-participant households respectively, theoretically the problem of household food insecurity can be eliminated. In other words, $0.1636,0.0344$ and 0.1262 quintals of annual per capita food grain was required to bring all the sample total food insecure, participant and non-participant households to the rank of food secure households respectively. As the estimated average food grain amount required to bring non-participant households out of food insecurity was estimated to be $4.08 \%$ higher than participant households, it can be said that the depth of non-participant households' food insecurity was slightly higher than participant households. The independent sample test was associated with a statistically significant effect $t(90.903)=5.793, p<0.01$ at $99 \%$ level of significance. This significant value of the t- test confirmed that the depth of household food insecurity amongst non-participants was fairly higher than their counterparts.

The limitation of household food insecurity gap measure is however is that it ignores the effect of inequality (deeper below or slight closer to the threshold) among the food insecure households. As a result, to identify the most food insecure sample households among the food insecure households, severity of food insecurity (Squared food insecurity gap index) was computed by assigning a higher weight $(\alpha=2)$. Accordingly, as shown in Table 7, 0.0329, 0.0052 and 0.0277 was the calculated severity of household food insecurity for the sample total food insecure households, food insecure participant and non-participant households respectively. These figures further implied that the severity of food insecurity among the sample food insecure households, food insecure participants and food insecure non-participant households was $3.29,0.52$ and $2.77 \%$ respectively. Moreover, the survey result also showed the existence of discrepancy among the food insecure households; where, participant households' severity of food insecurity was estimated to be $2.25 \%$ lower than non-participant households' severity of food insecurity. The independent sample test was associated with a statistically significant effect $t$ (116.462) $=6.593, \mathrm{p}<0.01$ at $99 \%$ level of significance. This significant value of the t- test declared that the severity of household food insecurity amongst participants was fairly lower than the severity of household food insecurity amongst non-participants.

Table 7. Food insecurity indices of the sample food insecure households

\begin{tabular}{c|c|c|c|c}
\hline \multirow{2}{*}{$\begin{array}{c}\text { Household Food } \\
\text { Insecurity indices }\end{array}$} & \multicolumn{2}{|c|}{ Food insecure Households (Ratio) } & \multirow{2}{*}{ Test-value } \\
\cline { 2 - 4 } & Total & Participants & Non-participants & \\
\hline $\begin{array}{c}\text { Incidence of food } \\
\text { insecurity }(\alpha=0)\end{array}$ & 0.4054 & 0.3451 & 0.4364 & $\begin{array}{c}2.578 \\
\text { (Chi-square) }\end{array}$ \\
\hline $\begin{array}{c}\text { Depth of food } \\
\text { insecurity }(\alpha=1)\end{array}$ & 0.0727 & 0.0153 & 0.0561 & $\begin{array}{c}5.793^{* * *} \\
\text { (t-value) }\end{array}$ \\
\hline $\begin{array}{c}\text { Severity of food } \\
\text { insecurity }(\alpha=2)\end{array}$ & 0.0329 & 0.0052 & 0.0277 & $\begin{array}{c}6.593^{* * *} \\
\text { (t-value) }\end{array}$ \\
\hline
\end{tabular}

***refers significant at 0.01 level

Source: Computed from field survey, 2016.

Though minimal in level, the result of this survey testified the prevalence of severe food shortage problem amongst the sample irrigation beneficiary households. In line with this empirical finding, as per the Focus Group Discussants', Key Informant Interview participants' opinion and personal observations, because of their lower poverty level and high level of food production and stock available, sample households were not beneficiaries of any food aid programmes in the survey year. As a result, participation in non-farm income generating activities, remittance from abroad, sell-off ruminant animals, and consumption of less expensive grain foods were mentioned as the common coping strategies employed by the sample transitory food insecure households to mitigate their food shortage problem. As food insecurity is a seasonal phenomenon, pronounced food shortage problem was reported to happen between the wet agricultural seasons (July) to the beginning of harvesting season (September) of the survey year. The 2015/16 integrated 
surveys on agriculture Ethiopia Socioeconomic Survey of [57], also exposes that in all parts of Ethiopia, June, July, August and September were flagged as particularly pronounced months of food insecurity.

\subsection{Correlation between HDDS, FCS, and NAF}

Various indicators of household food security had been employed by different organizations and researchers as one indicator at a time could not wholly explain household food security. Likewise, it is also important to evaluate the comparative performances of these indicators. To examine the validity of alternative measures of food security, measures of correlation such as Pearson or Spearman correlation coefficients can be employed [33]. For this study, I employed Pearson Correlation Coefficient to evaluate the consistency of household food security indicators used for this study. Accordingly, comparison analysis between indicators was made at cut-off points of less or equal to three food groups for the HDDS, less than 42 (poor and borderline food consumption) for FCS and less than $225 \mathrm{~kg}$ of annual food grain for Adult Equivalent NAF value. The strength of the relationship, the direction and the level of significance is presented below.

Table 8. Correlation between HDDS, FCS and NAF

\begin{tabular}{|c|c|c|c|c|}
\hline \multirow[b]{2}{*}{ Indicators } & \multirow{2}{*}{$\begin{array}{l}\text { Households } \\
\text { below the cut- } \\
\text { off point (\%) }\end{array}$} & \multicolumn{3}{|c|}{ Pearson correlation value } \\
\hline & & $\begin{array}{c}\text { HDDS } \\
\text { and FCS }\end{array}$ & $\begin{array}{l}\text { HDDS } \\
\text { and NAF }\end{array}$ & $\begin{array}{l}\text { FCS and } \\
\text { NAF }\end{array}$ \\
\hline HDDS & 68.5 & \multirow{3}{*}{$0.83^{* * *}$} & \multirow{3}{*}{$0.40 * * *$} & \multirow{3}{*}{$0.40^{* * *}$} \\
\hline FCS & 67.57 & & & \\
\hline NAF & 40.54 & & & \\
\hline
\end{tabular}

*** refers significant at 0.01 level

Source: Computed from field survey, 2016

The Pearson correlation matrix of this survey demonstrated in Table 9 shows that HDDS is significantly correlated (0.828) with FCS, whereas NAF had moderate correlation (0.402) with FCS as well as HDDS. Accordingly, the choice between the above mentioned indicators of household food security can be done based on purpose, time, and resource availability. These correlation results on the performance of specific indicators are found to be consistent with the previous empirical findings. [37] In their multi-country analysis of data from 10 countries found that correlation between number of food groups and energy consumption ranged from 0.085 to 0.329 . [61] In their comparative evaluation of dietary indicators used in food consumption assessment in Mozambique also found the correlation between food items and energy consumption to be 0.243 . Furthermore, a comparison of the Household Dietary Diversity and Food Consumption Scores by [62] in Burkina Faso, Lao People's Democratic Republic and northern Uganda showed significant correlation between these indicators and concluded that the choice of indicator of food security assessment and surveillance will vary depending on user's need.

Employing the t-test of association, an attempt was also made to identify the linkage between households' food security status and computed mean HDDS as well as FCS. Accordingly, as illustrated in Table 9, it was found that sample food secure and food insecure households had a computed 3.64 and 3.11 mean HDDS respectively. The independent sample test was associated with a statistically significant effect $t(307.043)=7.914, p<0.01$ at $1 \%$ probability level. This significant value of the t- test ascertained that sample food secure households enjoyed a relatively diversified meal than their counterparts.

The computed mean household FCS value displayed in Table 9 also showed variations among sample food secure (43.78) and food insecure households (41.21). The independent sample test was associated with a statistically significant effect $t(329.291)=8.317, \mathrm{p}<0.01$ at $1 \%$ probability level. This significant value of the t- test discovered that sample food secure household had a relatively higher FCS than food insecure households.

Table 9. Relationships between household food security status, HDDS and FCS

\begin{tabular}{c|c|c|c|c}
\hline Indicators & Food Security Status & Mean & SD & \multirow{2}{*}{ t-value } \\
\hline \multirow{2}{*}{ HDDS } & Food insecure & 3.11 & 0.40 & \multirow{2}{*}{$7.91^{* * *}$} \\
\cline { 2 - 4 } & Food secure & 3.64 & 0.80 & \\
\hline \multirow{2}{*}{ FCS } & Food insecure & 41.21 & 2.19 & \multirow{2}{*}{$8.32^{* * *}$} \\
\cline { 2 - 4 } & Food secure & 43.79 & 3.46 & \\
\hline
\end{tabular}

*** refers significant at 0.01 level, SD-Standard deviation

Source: Computed from field survey, 2016

\section{Conclusion}

Attaining food security for all people at all times remains a major challenge for many developing countries including Ethiopia. The current government of Ethiopia has been expanding and prioritize modern small scale irrigation projects as a means for achieving food security and reducing poverty at household level. Hence, this study has attempted to evaluate the household food security status of peri-urban modern small scale irrigation project beneficiary households. To achieve this objective, a combined household food security measures; Household Dietary Diversity Score (HDDS), Food Consumption Score (FCS) and Per Capita Net Food Availability (NAF) were employed.

The computed Household Dietary Diversity Score (HDDS), Food Consumption Score (FCS) and Per Capita Net Food Availability (NAF) measures of household food security exposed household's low household dietary diversity, food consumption score as well as food security status of the studied households. Furthermore, the comparative analysis also illustrated that the prevalence of household food insecurity, low household dietary diversity and food consumption was far more noticeable among non-participant households than participants. However, despite their significance difference in their household dietary diversity and food consumption scores, the Chisquare test statistical association result showed no significant differences between participant and nonparticipant households in their food security status at all probability levels. On the other hand, the FGT family of indices; food insecurity gap as well as severity of household food insecurity measure as well as the independent statistical t-test values of this survey indicated that the depth and severity of household food 
insecurity were relatively higher for non-participant households than participant households

Based on the empirical evidences of this survey it can be inferred that, the impact of peri-urban modern small scale irrigation projects on achieving household food security is minimal. This finding further questions the performance of irrigation schemes as a means of sustainable poverty reduction and food security attainment.

The computed Pearson correlation result showed that Household Dietary Diversity Score is significantly correlated with Food Consumption Score, whereas Net Available Food had moderate correlation with Food Consumption Score as well as Household Dietary Diversity Score. Moreover, the t-test statistical association also assured that sample food secure households had relatively better Household Dietary Diversity Score and Food Consumption Score than food insecure households. Cognizant to this, the finding of this study also supports and suggests the use of more than one indicators of household food security while assessing the food security status of households.

The per capita NAF grain analysis of a single year intake for a household tells more regarding seasonal household food shortage than showing chronic food insecurity in terms of poverty and its persistence over years and very unfortunately, in the survey year, the area was suffering a severe food shortage crisis due to too little rain and effects of the El Niño. Furthermore, the Chi-square test statistical association result showed no significant differences between participant and non-participant households in their food security status at all probability levels. This in turn inquires to further identify determinants of household food security and assess the impact of modern small scale irrigation projects on the beneficiary households' livelihood assets as commercialized agriculture has complex linkage with food security and livelihood.

This parcel of information is important for policy makers in the intervention areas of food insecurity and poverty reduction.

\section{Acknowledgements}

Research for this dissertation was supported in part by Open Society Foundations (OSF). Moreover, the author also gratefully acknowledges the financial support from Wollo University (WU) and thanks the interviewed households. The opinions expressed herein are my own and do not necessarily express the views of OSF and WU.

\section{References}

[1] Maxwell D., Jennifer C. and Bapu V. (2013.) How Do Different Indicators of Household Food Security Compare? Empirical Evidence from Tigray, Feinstein International Centre, Tufts University; Medford, USA.

[2] Pangaribowo E. H., Gerber N. and Torero M. (2013). Food and Nutrition Security Indicators; A Review, FOODSECURE working paper 04.

[3] Meskerem Ali and Degefa Tolossa (2015). Household Food security status and its determinants in Girar Jarso Woreda, North Shewa Zone of Oromia Region, Ethiopia. Journal of Sustainable Development in Africa, 17 (7), 118-137, Clarion University of Pennsylvania, Clarion, Pennsylvania.
[4] FAO (2008). Water for the rural poor; Interventions for improving livelihoods in Sub-Saharan Africa. In; Faures, J. M. and Santini, G. (eds). Food and Agriculture Organization, Rome.

[5] Babu S. and Sanyal P. (2009). Food security, poverty and nutrition policy analysis; statistical methods and applications, Elsevier Inc.

[6] Rosen S, Meade B, Murray A. (2015). International food security assessment, 2015-2025. GFA-26, U.S. Department of Agriculture, Economic Research Service, June 2015.

[7] FAO, IFAD and WFP (2015). The state of Food insecurity in the world 2015. Meeting the 2015 international hunger targets: taking stock of uneven progress. Rome, FAO

[8] Degefa Tolossa (2005). Rural livelihoods, poverty and food insecurity in Ethiopia, A case study at Erenssa and Garbi communities in Oromiya Zone, Amhara National Regional State. Unpublished PhD Thesis, Department of Geography, Norwegian University of Science and Technology, NTNU, Trondheim.

[9] UNDP (2009). Human development report 2009, New York: Palgrave Macmillan.

[10] Guyu Ferede (2015). Household Vulnerability to Green Famine; Component Based Analysis of Indicators in Belo-jiganfoy District, Benishangul-Gumuz Region, Ethiopia. Applied Science Reports, 9(3), 139-156.

[11] UNICEF (2017). Ethiopian Humanitarian Situation report.

[12] UNDP (2016). Human Development Report 2016. New York, USA.

[13] UNDESA (2015). World Urbanization prospects: The 2014 Revision, (ST/ESA/SER.A/366), United Nations, Department of Economic and Social Affairs, Population Division, New York, USA.

[14] WFP (2009). Summary of food security and Vulnerability in selected urban centres of Ethiopia. Addis Ababa, Ethiopia.

[15] Samson Kassahun and Alok Tiwari (2012). Urban Development in Ethiopia: Challenges and Policy Responses. The IUP journal of Governance and public policy, Vol. 7 no.1.

[16] MoFED (2012). Ethiopia's progress towards eradicating poverty: an interim report on poverty analysis study (2010/11). Development planning and research directorate, FDRE, Addis Ababa.

[17] Degefa Tolossa (2010). Some realities of the urban poor and their food security situations: a case study of Berta Gibi and Gemechu Safar in the city of Addis Ababa, Ethiopia. Environment and Urbanization, 22(1), 179-198, IIED.

[18] Dessalegn Rahmato (2013). Food security and safety Nets: Assessment and challenges, in Dessalegn Rahmato, Alula Pankhurst and Jan-Gerrit Van Uffelen (eds), Food Security, Safety Nets and Social Protection in Ethiopia. Addis Ababa: FSS.

[19] MoFED (2002). Poverty profile of Ethiopia, Addis Ababa, Ethiopia.

[20] FAO (2001). Urban And Peri-Urban Agriculture; A briefing guide for the successful implementation of Urban and Peri-urban Agriculture in Developing Countries and Countries of Transition, Rome, Italy.

[21] Veenhuizen R. V. and Danso G. (2007). Profitability and Sustainability of Urban and Peri- urban agriculture, Agricultural Management, marketing and finance occasional paper, FAO, Rome.

[22] Awulachew, S. B., Merrey, D.J., Kamara, A. B., Van Koopen, B., Penning de Vries, F and Boelee, E., and Makombe, G. (2005). Experiences and Opportunities for Promoting Small Scale/Micro Irrigation and Rainwater Harvesting For Food Security in Ethiopia. Colombo, Sri Lanka: IWMI. V.86p. (Working paper 98).

[23] Awlachew, S. B., Erkosa, T. and Namara, R. E. (2010). Irrigation Potential in Ethiopia: Constraints and Opportunities for Enhancing the System, International Water Management Institute.

[24] Nugusse Zeweld (2013). Food Security through Small Scale Irrigation; Case Study from Northern Ethiopia, Masters unpublished thesis Ghent University, Belgium.

[25] Solomon Cherre (2006). Irrigation policies, strategies and institutional support conditions in Ethiopia in Awulachew S. B., Menker M., Abesha D., Atnafe T., Wondimkun Y. (eds) (2006). Best Practices and Technologies for Small Scale Agricultural Water Management in Ethiopia. Proceeding of a MoARD/MoWR/USAID/IWMI symposium and exhibition held at Ghion Hotel, Addis Ababa, Ethiopia 7-9 March 2006. Colombo, Sri Lanka; International Water Management Institute, .190 pp.

[26] KGVDP (2015). Modern small scale Irrigation project beneficiary households up to 2015, unpublished report, Kobo, Ethiopia. 
[27] Goitom Sisay (2009). Rural-urban marketing linkages and its implication for integrated development, the case of Kobo town and its surrounding Kebeles, unpublished M.A thesis, Department of Geography and Environmental Studies, Addis Ababa University, Ethiopia

[28] CSA (2010). The 2007 population and Housing census of Ethiopia: results from country level statistical report. FDRE, Population Census Commission

[29] Kothari C.R. (2004). Research methodology; methods and techniques, Second revised edition, new age international (P) limited publishers.

[30] Creswell J. (2012). Educational research; planning, conducting, and evaluating quantitative and qualitative research, fourth edition, Pearson.

[31] Babbie E. (1990). Survey Research Methods. Belmont; Wadsworth Publishing.

[32] Creative Research Systems (CRS) (2012). Sample Size Formulas for our Sample Size Calculator

http;//www.surveysystem.com/sample-size-formula.htm accessed on January 25, 2015.

[33] Hoddinott J. (ed) (2001). Methods for Rural Development Projects. Food security in practice, Vol 1, IFRI, Washington D.C.

[34] Wiesmann D., J. Hoddinott, N.-L. Aberman and M. Ruel. (2006). Review and Validation of Dietary Diversity, food frequency and other proxy indicators of household Food security, report submitted to World Food Programme, Rome, by IFPRI.

[35] Maxwell D. (2008). The coping strategy Index: a tool for rapid Measurement of Household Foods and the impact of food aid programs in Humanitarian Agencies, Field method manual, 2nd TANGO, USAID, WFP and CARE.

[36] CSA (2005). The 2005 National statistics, Addis Ababa, Ethiopia.

[37] Hoddinott J. and Yohannes Y. (2002). Dietary diversity as a food security indicator. Food consumption and Nutrition division discussion paper. Washington D.C IFPR.

[38] Arimond M. and M. T. Ruel (2004). Dietary Diversity, dietary quality and child Nutritional status: Evidence from eleven demographic and health surveys. Washington D.C. Food and Nutrition Technical Assistance (FANTA) project, Academy for Educational Development (AED).

[39] Hatloy A., Halland J., Diarra M., and Oshaug A. (2000). Food Variety, Socio-Economic Status and Nutritional Status in Urban and Rural Areas In Koutiala (Mali). Public. Health Nutr.3:57-65.

[40] Degeye Goshu, Belay Kassa and Mengistu Ketema (2013) Measuring Diet Quantity and Quality Dimensions of Food Security in Rural Ethiopia, Journal of Development and Agricultural Economics, 5 (5), 174-185.

[41] WHO/FAO (1998). Preparation and use of Food based dietary Guidelines. Report of a joint WHO/FAO consultation. WHO/FAO technical report series No.880 Geneva.

[42] Ruel M. (2006). Operationalizing Dietary Diversity: A review of Measurement Issues and Research Priorities. Food Consumption and Nutrition Division, International Food Policy research institute (IFPRI), Washington D.C.

[43] FAO (2011). Women in Agriculture; Closing the gender gap for development. Rome, Italy; FAO and Agriculture Organization of the United Nations.

[44] Kassie G.T., Asfaw W., Zeleke G., and Scott D. (2008). The Nexus of Migration, HIV/AIDS and Food Security in Ethiopia, Global Mountain Programme of the CGIAR, Addis Ababa, Ethiopia.

[45] Arega Bazezew (2012). Determining Food security Indicators at Household level in Drought prone areas of the Amhara Region of Ethiopia: the case of Lay Gaint District, Ethiopian Journal of Environmental Studies and Management (EJESM), Vol.5 No.4.

[46] Girma Nega, Melkie Endris, Degnet Teferi, Amanuel Nana and Rigbe W/Michael (2015). Dietary Diversity and Associated factors among Rural Households in South Gonder Zone,
Northwest Ethiopia, feed the future- Research award, Bahir Dar, Ethiopia.

[47] Getnet Mekuria, Yalewsew Wubneh and Tilahun Tewabe (2017) Household Dietary Diversity and Associated Factors among residents of Finote Selam town, North West Ethiopia: a cross sectional study, BMC Nutrition (2017) 3; 28.

[48] WFP (2008). Food consumption analysis Calculation and use of the food consumption score in food security analysis, Vulnerability Analysis and Mapping Branch, Rome, Italy.

[49] Ephrem Tegegne (2015). Livelihoods and Food Security In The Small Urban Centres of Ethiopia; The Case Of Durame, Wolenchiti And Debre Sina Towns, a PhD unpublished thesis, Department of Geography and Environmental Studies, Addis Ababa University, Addis Ababa, Ethiopia.

[50] Messay Mulugeta (2010). Food Security Attainment Role of Urban Agriculture; a Case Study from Adama Town, Central Ethiopia. Journal of Sustainable Development in Africa Vol 12, No..3, pp. 223-249, Clarion University of Pennsylvania, Clarion, Pennsylvania.

[51] Getinet Kebede (2011). Linking Small-Scale Irrigation and Household Food Security in Drought Prone Area of North East Ethiopia; A Case Study of Alawuha Irrigation Scheme in Gubalafto Wereda, North Wollo Zone, unpublished M.Sc thesis, Institute Of Development Studies, Addis Ababa University, Ethiopia.

[52] Gutu Tesso (2015). Why the urban households remain Food insecure in Developing countries? Empirical Evidence from Nekemte Town of Ethiopia, International Journal of Managerial Studies and Research (IJMSR), 3(10), 108-117.

[53] Foster J., J. Greer and E. Thorbecke (1984). A class of Decomposable Poverty Measures. Econometrica, Vol.52 ,No.3 (May,1984) pp 761-766.

[54] FAO (2003). Trade reforms and food security - conceptualizing the linkages. FAO, Rome.

[55] FAO (2013). The state of food insecurity in the world: the multiple dimensions of food security. FAO, Rome http://www.fao.org/docrep/016/i3027e/i3027e.pdf accessed on 24/01/2015.

[56] Ruel M., James L. Garrett, Saul S.Morris, Daniel Maxwell, Arne Oshaug, Patrice Engle, Purnima Menon, Alison Slack, and Lawrence Haddad. (1998). urban challenges to Food and Nutrition security: a review of Food security, Health and Caregiving in the cities. FCND Discussion paper No.51, Food Consumption and Nutrition Division, International Food Policy research institute (IFPRI), Washington D.C.

[57] CSA and World Bank (2017). LSMS-Integrated Survey on Agriculture Ethiopia Socio Economic Survey (ESS) 2015/16, Addis Ababa, Ethiopia.

[58] CSA and WFP (2014). Comprehensive Food security and Vulnerability Analysis (CFSVA), Ethiopia.

[59] Haile Tesfay (2008). Impact of Irrigation Development on Poverty Reduction in Northern Ethiopia, a PhD unpublished Thesis, Department of Food Business and Development, National University of Ireland, Cork.

[60] World Bank (2006). Ethiopia: Managing Water Resources to maximize Sustainable growth, A World Bank Water Resource Assistance Strategy for Ethiopia, Washington, D.C.

[61] Rose D., S. Chotard, L. Oliveira, N. Mock and M. Libombo (2008). Comparative evaluation of dietary indicators used in food consumption assessment of at risk populations, Food and Nutrition Bulletin, vol, 29, No 2, pp 113-122.

[62] Kennedy G., Berardo A., Papavero C., Horjus P., Ballard T., Dop MC., Delbaere J. and Brouwer ID. (2010). Proxy measures of household food consumption for food security assessment and surveillance: comparison of the household dietary diversity and food consumption scores, Public Health Nutrition: 13(12), pp. 2010-2018. 